\title{
Quantity and quality of mental activities and the risk of incident mild cognitive impairment
}

Janina Krell-Roesch, PhD, Jeremy A. Syrjanen, MSc, Maria Vassilaki, MD, PhD, MPH, Mary M. Machulda, PhD, Michelle M. Mielke, PhD, David S. Knopman, MD, Walter K. Kremers, PhD, Ronald C. Petersen, MD, PhD, and Yonas E. Geda, MD, MSc

Neurology ${ }^{\circledR}$ 2019;93:e548-e558. doi:10.1212/WNL.0000000000007897

\section{Abstract}

\section{Objective}

To investigate whether timing, number, and frequency of mentally stimulating activities in midlife and late life are associated with the risk of incident mild cognitive impairment (MCI).

\section{Methods}

We conducted a prospective cohort study in the setting of the population-based Mayo Clinic Study of Aging in Olmsted County, Minnesota, including 2,000 individuals aged $\geq 70$ years who were cognitively unimpaired at baseline and were followed for a median of 5.0 years. Participants completed a self-reported survey on timing, number, and frequency of engagement in 5 mentally stimulating activities (reading books, computer use, social activities, playing games, craft activities) at baseline.

\section{Results}

The risk of incident MCI was significantly reduced for participants who engaged in social activities (hazard ratio [95\% confidence interval] 0.80 [0.64-0.99]) and playing games (0.80 [0.66-0.98]) in both late life and midlife combined. Using a computer was associated with a decreased risk regardless of timing (not late life but midlife: 0.52 [0.31-0.88]; late life but not midlife: 0.70 [0.56-0.88]; late life and midlife: 0.63 [0.51-0.79]). Craft activities were associated with a reduced risk of incident $\mathrm{MCI}$ only when carried out in late life but not midlife (0.58 [0.34-0.97]). Furthermore, engaging in a higher number of activities in late life was associated with a significantly reduced risk of incident MCI (any 2 activities: 0.72 [0.53-0.99], any 3: 0.55 [0.40-0.77], any 4: $0.44[0.30-0.65]$, all 5: 0.57 [0.34-0.96]).

\section{Conclusion}

Engaging in a higher number of mentally stimulating activities, particularly in late life, is associated with a decreased risk of MCI among community-dwelling older persons.

\author{
Correspondence \\ Dr. Geda \\ geda.yonas@mayo.edu
}

\section{RELATED ARTICLE}

\section{Editorial}

Frequency, number, and timing of mental activity and risk of mild cognitive impairment

Page 237 


\section{Glossary}

$\mathrm{AD}=$ Alzheimer disease; $\mathrm{CDR}$ = Clinical Dementia Rating Scale; $\mathrm{IQR}$ = interquartile range; $\mathrm{MCI}=$ mild cognitive impairment; MCSA = Mayo Clinic Study of Aging.

Mentally stimulating activities are modifiable lifestyle factors that are easily available to anyone at no or limited cost. Given the current absence of an effective treatment or cure for Alzheimer disease $(\mathrm{AD})$, there is growing interest in the investigation of lifestyle factors in the context of brain aging. It is particularly crucial to examine the presymptomatic stages of $\mathrm{AD}$ and mild cognitive impairment (MCI) that may provide a window of opportunity for potential preventive strategies. Indeed, there is growing evidence for a link between mental, cognitive, or intellectual activities and a reduced risk of cognitive decline. For example, a meta-analysis including 19 studies revealed that participation in these activities is associated with a reduced risk of cognitive impairment and dementia. ${ }^{1}$ In addition, our group has shown that cognitively unimpaired older persons who engage in specific mentally stimulating activities, i.e., reading books, computer use, social activities, playing games, and craft activities, have a decreased risk of new onset of $\mathrm{MCI}^{2}$ However, we only focused on activities carried out in late life and it remains unclear whether the risk of incident MCI is also associated with mentally stimulating activities carried out in midlife. Therefore, we have now conducted a prospective cohort study among cognitively unimpaired, community-dwelling persons aged $\geq 70$ years to address 3 research questions that arose from our previously reported findings: (1) Timing of engagement: Does the risk of incident MCI differ between persons who engaged in mentally stimulating activities in midlife and late life combined as compared to persons who only engaged in these activities in either midlife or late life? (2) Number of activities: Does the risk of incident MCI differ between persons who engage in several activities combined as compared to persons who engage in only one activity? (3) Frequency of engagement: Does the risk of incident MCI differ between persons who engage in mentally stimulating activities more frequently as compared to persons who engage less frequently?

\section{Methods}

\section{Design and sample}

This study was derived from the longitudinal, populationbased Mayo Clinic Study of Aging (MCSA) in Olmsted County, Minnesota. ${ }^{3}$ We included cognitively unimpaired individuals aged $\geq 70$ years who had completed a self-reported questionnaire on engagement in midlife and late-life mentally stimulating activities at baseline and had undergone cognitive evaluation at baseline and on average every 15 months during follow-up. The final cohort consisted of 2,000 persons who were followed forward in time for a median of 5.0 years until they either developed new onset of MCI or remained cognitively unimpaired. The study flow chart is provided in figure 1. Data reported in this study were collected from June 2006 to December 2016.

\section{Standard protocol approvals, registrations, and patient consents}

The institutional review boards of the Mayo Clinic and Olmsted Medical Center in Rochester, Minnesota, approved the MCSA protocols. All study participants provided written informed consent.

Figure 1 Study flow chart

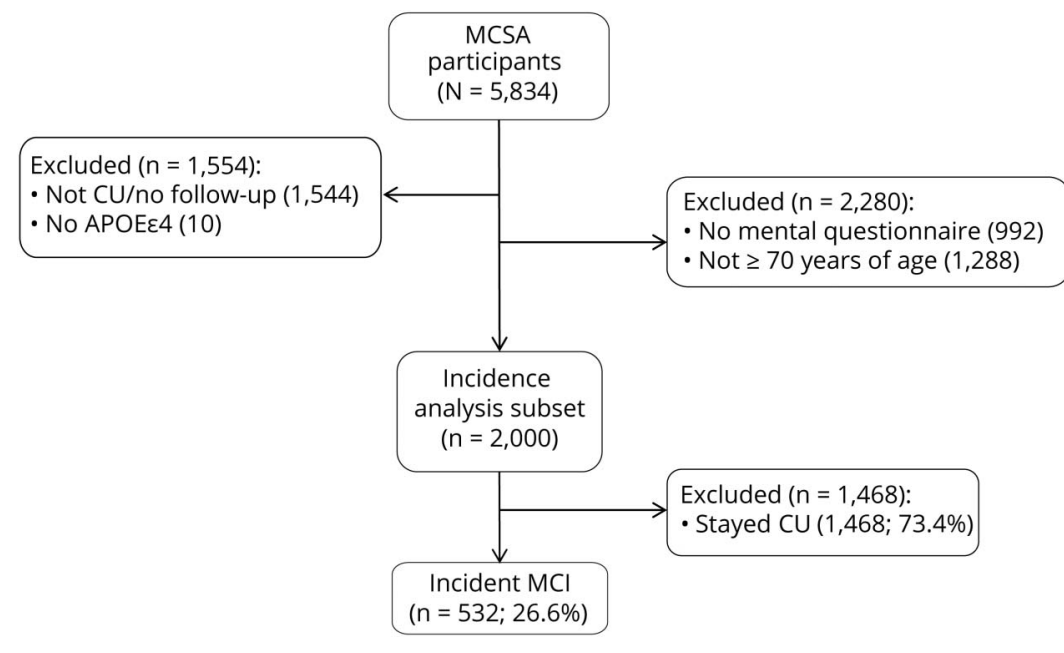

$\mathrm{CU}=$ cognitively unimpaired; $\mathrm{MCl}=$ mild cognitive impairment; MCSA = Mayo Clinic Study of Aging. 


\section{Clinical evaluation}

Participants underwent a face-to-face evaluation including a neurologic examination, risk factors ascertainment, and neuropsychological testing. The reader is referred elsewhere for details on the face-to-face evaluation. ${ }^{3}$ Briefly, the neurologic evaluation comprised a neurologic history review, administration of Short Test of Mental Status, ${ }^{4}$ and a neurologic examination. The risk factor assessment interview was conducted by a study coordinator and included the Clinical Dementia Rating Scale (CDR). ${ }^{5}$ Neuropsychological testing was administered by a psychometrist in order to assess performance in 4 cognitive domains: memory (delayed recall trials from Auditory Verbal Learning Test, ${ }^{6}$ Wechsler Memory Scale-Revised, ${ }^{7}$ Logical Memory, and Visual Reproduction subtests), language (Boston Naming Test, ${ }^{8}$ category fluency ${ }^{9}$ ), visuospatial skills (Wechsler Adult Intelligence Scale-Revised, ${ }^{10}$ Picture Completion and Block Design subtests), and attention/executive function (Trail-Making Test Part B, ${ }^{11}$ Wechsler Adult Intelligent Scale-Revised, ${ }^{10}$ Digit Symbol Substitution subtest). An expert consensus panel consisting of physicians, study coordinators, and neuropsychologists reviewed the results for each participant and determined whether a participant was cognitively unimpaired or had MCI. Individuals were classified as cognitively unimpaired based on normative data developed in this community. ${ }^{12-15}$ For MCI, the revised Mayo Clinic criteria for $\mathrm{MCI}^{16,17}$ were used: (1) cognitive concern expressed by a physician, informant, participant, or nurse; (2) impairment in one or more cognitive domains (executive functions, memory, language, or visuospatial skills); (3) essentially normal functional activities; and (4) absence of dementia. Participants with MCI had a CDR score of 0 or 0.5 ; however, the final diagnosis of MCI was based on all available data.

\section{Assessment of mentally stimulating activities}

Details of the measurement of mentally stimulating activities in the MCSA have been reported elsewhere. ${ }^{18,19}$ Briefly, we modified previously validated instruments to measure engagement in these activities. ${ }^{20-22}$ We defined the following activities as exposures of interest based on results from our previously published case-control ${ }^{18}$ and cohort studies ${ }^{2}$ : reading books, craft activities (e.g., pottery, quilting, or sewing), computer activities, playing games (e.g., playing cards or doing crossword puzzles), and social activities (e.g., going to the movies or going out with friends). The frequency at which each participant engaged in each mentally stimulating activity was assessed by a structured survey with ordinal responses (once a month or less, 2-3 times a month, 1-2 times per week, 3-4 times per week, 5-6 times per week, and daily). Participants were asked to provide information about engagement in these activities in midlife (between the ages of 50 and 65 years) and late life (in the year prior to study participation).

\section{APOE genotyping}

Blood was drawn from the study participants after receiving informed consent. DNA was amplified by means of PCR, and
APOE genotyping was determined by standard methods. ${ }^{23}$ The genotypes were determined by laboratory technicians who were kept unaware of clinical characteristics.

\section{Statistical analysis}

We calculated hazard ratios and $95 \%$ confidence intervals by using Cox proportional hazards models with age as the time scale and after adjusting for sex, education, and APOE genotype status. To address the first research question on the timing of engagement, we compared timing of engaging (not late life but midlife; late life but not midlife; late life and midlife) vs not late life or midlife (defined as reference group) for each of the 5 mentally stimulating activities of interest (i.e., reading books, craft activities, computer activities, playing games, and social activities). Not engaging in an activity was defined as 2-3 times per month or less and engaging in an activity was defined as 1-2 times per week or more. To address the second research question regarding combination of activities, we created 5 groups of activities (any 1 activity; any 2 activities such as reading books and craft activities; any 3 activities such as craft activities, playing games, and social activities; any 4 activities such as reading books, craft activities, computer activities, and social activities; all 5 activities) and compared it with no activities (defined as reference group), separately for late-life and midlife. Similar to the first research question, we defined not engaging in an activity as $2-3$ times per month or less and engaging in an activity as $1-2$ times per week or more. To address the third research question on frequency of engagement, we conducted the analyses separately for the 5 different mentally stimulating activities, and for late-life and midlife. We compared mentally stimulating activities carried out at different frequencies (2-3 times/mo; 1-2 times/wk; 3-4 times/wk; 5-6 times/wk; and every day) vs once a month or less (defined as reference group) in predicting the risk of incident MCI. The statistical analyses were conducted using the conventional 2-tailed $\alpha$ level of 0.05 and performed with SAS 9.4 (SAS Institute, Inc, Cary, NC). We did not adjust our analyses for cognition at baseline for the following reason: $\mathrm{MCI}$ is a chronic condition that develops gradually over many years. As a result, in an observational study with 5 years of follow-up, factors that contribute to cognitive decline (and therefore incident MCI) are also likely to be associated with the level of cognition at the onset of the observation period. Therefore, adding a term for baseline level of cognition would "over control" our model.

\section{Data availability}

Data may be shared per request from a qualified investigator in accordance with the MCSA data-sharing protocol.

\section{Results}

At baseline, we included 2,000 cognitively unimpaired persons aged $\geq 70$ years $(49.9 \%$ male) who had completed the mentally stimulating activities assessment and cognitive evaluation. We followed this cohort forward in time for 
a median of 5.0 years (interquartile range [IQR] 2.5, 7.7 years), at which time 532 participants developed new onset of MCI. The median age at baseline was 77.8 years (IQR 74.2, 82.8 years) and the median level of education was 14 years (IQR 12, 16 years). A total of 534 participants (26.7\%) were APOE $\varepsilon 4$ carriers (table 1). The correlations between global cognition at baseline and mental activities were fairly low. The coefficients for midlife activities ranged from $r=0.07$ (social activities) to $r=0.25$ (computer activities); for late-life activities, the coefficients ranged from $r=0.09$ (social activities) to $r=0.31$ (computer activities).

\section{Association of timing of engagement with risk of incident $\mathrm{MCl}$}

Participants who engaged in computer use only in midlife, only in late life, or in both late and midlife combined had a significantly decreased risk of developing new onset of MCI. For craft activities, engaging in late but not midlife was associated with a decreased risk and for social activities and playing games, engaging in both late and midlife combined was associated with a decreased risk of incident MCI (table 2 and figure 2).

\section{Association of number of activities with risk of incident $\mathrm{MCl}$}

Engaging in as few as 2 activities up to as high as all 5 activities in late life was associated with a significantly decreased risk of incident MCI. There was no significant association between number of mentally stimulating activities carried out in midlife and the risk of new onset of MCI (table 3 and figure 3).

\section{Association of frequency of late-life activities with risk of incident $\mathrm{MCl}$}

Reading books or playing games (2-3 times/mo; 5-6 times/ wk; every day) was significantly associated with a decreased risk of incident MCI. Similarly, using a computer (5-6 times/ wk; every day) was associated with a decreased risk of incident MCI. Engaging in craft activities (2-3 times/mo; 1-2 times/ wk; 5-6 times/wk); and engaging in social activities (as little as 2-3 times/mo; 1-2 times/wk; 3-4 times/wk) was also associated with a significantly decreased risk of incident MCI (table 4).

Table 1 Demographic characteristics of participants who were cognitively unimpaired at baseline

\begin{tabular}{ll}
\hline Variable & Total $(\mathbf{n}=\mathbf{2 , 0 0 0})$ \\
\hline Male, $\mathbf{n}(\%)$ & $998(49.9)$ \\
\hline Age, $\mathbf{y}$, median (IQR) & $77.8(74.2,82.8)$ \\
\hline Education, $\mathbf{y}$, median (IQR) & $14(12,16)$ \\
\hline APOE \&4 carrier, $\mathbf{n}(\%)$ & $534(26.7)$ \\
\hline Follow-up, $\mathbf{y}$, median (IQR) & $5.0(2.5,7.7)$ \\
\hline
\end{tabular}

Abbreviation: $I Q R=$ interquartile range.

\section{Association of frequency of midlife activities with risk of incident $\mathrm{MCl}$}

Reading books every day, using a computer 3-4 times/wk or more (3-4 times/wk; 5-6 times/wk; every day), engaging 2-3 times/mo in craft activities or social activities, and engaging 1-2 times/wk in social activities was associated with a decreased risk of new onset of MCI. Playing games at any frequency (2-3 times/mo; 1-2 times/wk; 3-4 times/wk; 5-6 times/wk) was also associated with a decreased risk of incident MCI (table 5).

\section{Discussion}

We report that engaging in mentally stimulating activities was overall associated with a reduced risk of incident MCI among community-dwelling older adults who were cognitively unimpaired at baseline. With regard to timing of engagement, we observed that the risk of incident MCI was significantly reduced for participants who engaged in social activities and playing games in both late and midlife combined. Using a computer was associated with a decreased risk of incident $\mathrm{MCI}$ regardless of timing. Craft activities were associated with a reduced risk of incident MCI only when carried out in late life but not midlife. The point estimates for reading books and engaging in social activities in midlife but not late life were greater than 1.00, which indicates an increased risk of incident $\mathrm{MCI}$, albeit not significant.

Furthermore, engaging in any 2 or more mentally stimulating activities in late life was associated with a decreased risk of incident MCI, with point estimates ranging between 0.72 for any 2 activities and 0.44 for any 4 activities. Thus, one may conclude that engaging in a higher number of mentally stimulating activities in late life may be more beneficial with regard to the risk of new onset of MCI than engaging in a lower number. However, of note, the point estimate for engaging in all 5 activities was slightly higher than for engaging in any 3 or any 4 activities, but still below 1.00, indicating a decreased risk of incident MCI as compared to the reference group. Finally, there was no consistent doseresponse pattern for the associations between frequency of engagement in mentally stimulating activities and the risk of incident MCI. For example, for reading books, computer use, and playing games, be it in late life or midlife, we observed a trend for smaller point estimates with higher frequency of engagement, indicating a reduced risk of incident MCI among persons who engaged more frequently in these activities than persons who engaged less frequently. However, we did not observe such pattern for craft activities and social activities.

Our findings that, on average, engaging in mentally stimulating activities is associated with reduced risk of incident MCI is in line with other population-based cohort studies that also reported an association between participation in cognitive activities and a decreased risk of incident amnestic $\mathrm{MCI}^{24}$ incident cognitive impairment, ${ }^{25}$ or incident dementia. ${ }^{20,26,27}$ 
Table 2 Association between timing of engagement in mentally stimulating activities and the risk of incident mild cognitive impairment $(\mathrm{MCl})$

\begin{tabular}{|c|c|c|c|c|}
\hline Variable & No. at risk & No. with incident $\mathrm{MCl}$ & $\mathrm{HR}(95 \% \mathrm{Cl})$ & $p$ Value \\
\hline \multicolumn{5}{|l|}{ Reading books } \\
\hline Not late life or midlife & 745 & 209 & 1.00 [reference] & \\
\hline Not late life but midlife & 136 & 45 & $1.22(0.87-1.70)$ & 0.24 \\
\hline Late life but not midlife & 184 & 57 & $1.01(0.75-1.36)$ & 0.94 \\
\hline Late life and midlife & 935 & 221 & $0.83(0.67-1.01)$ & 0.07 \\
\hline \multicolumn{5}{|l|}{ Computer use } \\
\hline Not late life or midlife & 786 & 277 & 1.00 [reference] & \\
\hline Not late life but midlife & 77 & 15 & $0.52(0.31-0.88)$ & 0.01 \\
\hline Late life but not midlife & 376 & 103 & $0.70(0.56-0.88)$ & $<0.01$ \\
\hline Late life and midlife & 761 & 137 & $0.63(0.51-0.79)$ & $<0.01$ \\
\hline \multicolumn{5}{|l|}{ Craft activities } \\
\hline Not late life or midlife & 1,170 & 307 & 1.00 [reference] & \\
\hline Not late life but midlife & 309 & 98 & $1.01(0.80-1.27)$ & 0.96 \\
\hline Late life but not midlife & 86 & 15 & $0.58(0.34-0.97)$ & 0.04 \\
\hline Late life and midlife & 435 & 112 & $0.85(0.68-1.06)$ & 0.15 \\
\hline \multicolumn{5}{|l|}{ Social activities } \\
\hline Not late life or midlife & 900 & 247 & 1.00 [reference] & \\
\hline Not late life but midlife & 303 & 94 & $1.19(0.94-1.51)$ & 0.15 \\
\hline Late life but not midlife & 195 & 59 & $1.05(0.79-1.40)$ & 0.75 \\
\hline Late life and midlife & 602 & 132 & $0.80(0.64-0.99)$ & 0.04 \\
\hline \multicolumn{5}{|l|}{ Playing games } \\
\hline Not late life or midlife & 690 & 195 & 1.00 [reference] & \\
\hline Not late life but midlife & 164 & 46 & $0.84(0.61-1.16)$ & 0.29 \\
\hline Late life but not midlife & 269 & 69 & $0.78(0.59-1.03)$ & 0.08 \\
\hline Late life and midlife & 877 & 222 & $0.80(0.66-0.98)$ & 0.03 \\
\hline
\end{tabular}

Abbreviations: $\mathrm{Cl}=$ confidence interval; $\mathrm{HR}=$ hazard ratio.

Models adjusted for age (as the time scale), sex, education, and APOE $\varepsilon 4$ genotype status.

Our study expands on previously published research and, to our knowledge, may be one of the few that examined the associations between different measures of engagement in mentally stimulating activities, i.e., timing, number, and frequency, and the risk of incident MCI in a large populationbased sample of cognitively unimpaired persons. In the past, investigators from Rush University have reported a doseresponse pattern for frequency of cognitively stimulating activities and risk of incident $\mathrm{AD}$, i.e., they showed that persons who reported baseline cognitive activities at high frequency (90th percentile) had a risk reduction of $47 \%$ of developing new onset of $\mathrm{AD}$ as compared to persons in the 10th percentile. $^{28}$ In another article, the same group reported that higher frequency of cognitive activity is also associated with a decreased risk of incident $\mathrm{MCI} .^{29}$ In our study, we also observed a trend for a decreased risk of incident MCI as indicated by smaller point estimates for reading books, computer use, and playing games, albeit failing to establish an overall consistent dose-response relationship between frequency and risk of incident MCI for all 5 mentally stimulating activities. The difference between the findings from Rush University investigators and ours may be due to different methodology, i.e., they used a composite measure of cognitive activity (cognitive score) and compared percentiles, whereas we compared frequency groups separately for various mentally stimulating activities. We deliberately did not calculate a composite measure since the 5 activities were minimally intercorrelated in our dataset (coefficients ranged from $r=$ 
Figure 2 Association between timing of engagement in mentally stimulating activities and the risk of incident mild cognitive impairment

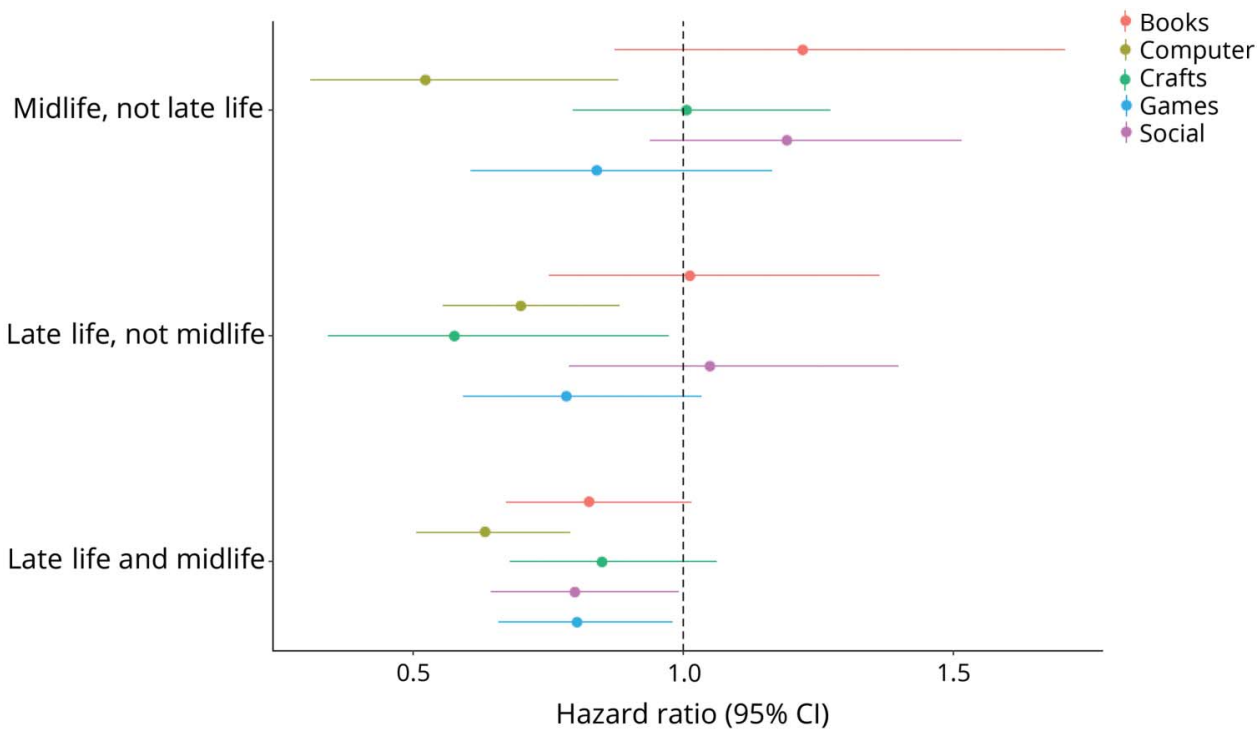

$\mathrm{Cl}=$ confidence interval .

0.05 to $r=0.19$ for late-life activities, and from $r=0.01$ to $r=$ 0.26 for midlife activities). Therefore, there is merit in presenting the activities separately. In addition, a study from Columbia University found that a higher degree of leisure activities was significantly associated with a decreased risk of incident $\mathrm{AD} \cdot{ }^{30}$ Another study from Chinese investigators also showed that participants who engaged in a higher number of late-life leisure activities had more preserved cognitive function than participants who engaged in fewer activities. ${ }^{31}$ This is in line with our observation that engaging in a higher

Table 3 Association between number of mentally stimulating activities in late or midlife and the risk of incident mild cognitive impairment (MCl)

\begin{tabular}{|c|c|c|c|c|}
\hline Variable & No. at risk & $\begin{array}{l}\text { No. with incident } \\
\mathrm{MCl}\end{array}$ & HR $(95 \% \mathrm{CI})$ & $p$ Value \\
\hline \multicolumn{5}{|l|}{ Late-life activities } \\
\hline No activities & 136 & 55 & 1.00 [reference] & \\
\hline Any 1 activity & 399 & 127 & $0.80(0.58-1.10)$ & 0.18 \\
\hline Any 2 activities & 555 & 149 & $0.72(0.53-0.99)$ & 0.04 \\
\hline Any 3 activities & 520 & 123 & $0.55(0.40-0.77)$ & $<0.01$ \\
\hline Any 4 activities & 299 & 57 & $0.44(0.30-0.65)$ & $<0.01$ \\
\hline All 5 activities & 91 & 21 & $0.57(0.34-0.96)$ & 0.03 \\
\hline \multicolumn{5}{|l|}{ Midlife activities } \\
\hline No activities & 193 & 62 & 1.00 [reference] & \\
\hline Any 1 activity & 417 & 138 & $1.24(0.92-1.68)$ & 0.16 \\
\hline Any 2 activities & 466 & 121 & $0.93(0.68-1.27)$ & 0.63 \\
\hline Any 3 activities & 515 & 118 & $0.81(0.59-1.11)$ & 0.19 \\
\hline Any 4 activities & 340 & 77 & $0.79(0.56-1.12)$ & 0.18 \\
\hline All 5 activities & 69 & 16 & $0.83(0.47-1.45)$ & 0.50 \\
\hline
\end{tabular}

Abbreviations: $\mathrm{Cl}$ = confidence interval; $\mathrm{HR}$ = hazard ratio.

Models adjusted for age (as the time scale), sex, education, and APOE $\varepsilon 4$ genotype status. 
Figure 3 Association between number of mentally stimulating activities in late or midlife and the risk of incident mild cognitive impairment

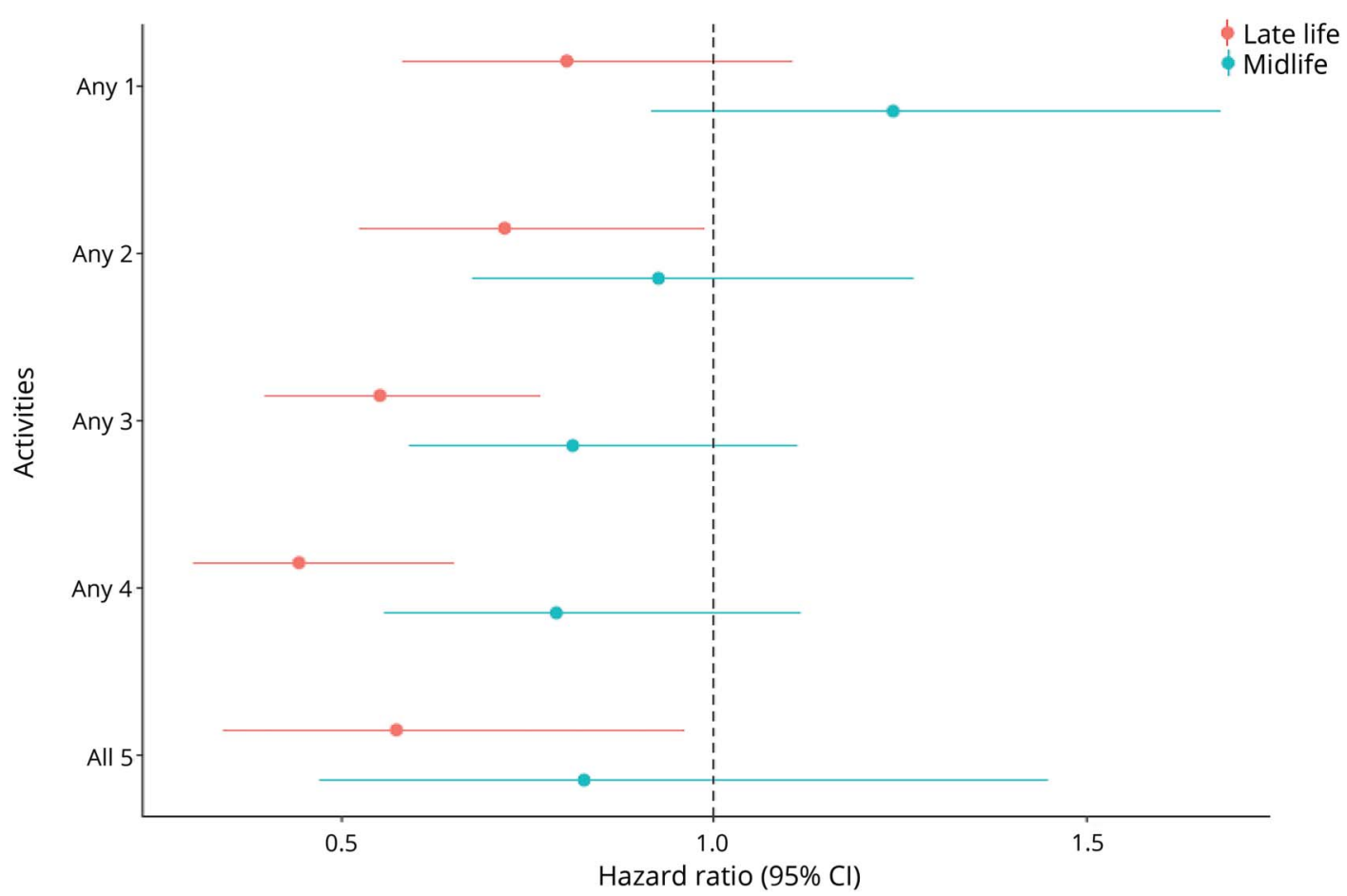

$\mathrm{Cl}=$ confidence interval.

number of activities in late life was associated with a decreased risk of incident MCI.

With regard to timing of cognitive activities, it has been reported that engaging in cognitive and social activities in midlife is associated with better late-life cognitive scores. ${ }^{32,33}$ In our study, we built on this existing knowledge by further comparing the risk of incident MCI for 4 different time groups of engagement in mentally stimulating activities, i.e., only midlife, only late life, mid- and late life combined, and not mid- or late life. Specifically, our analyses revealed a difference between late-life vs midlife activities in terms of their associations with incident $\mathrm{MCI}$, i.e., mentally stimulating activities carried out in late life were more relevant to the risk of new onset MCI than midlife activities.

Many hypotheses have been proposed in the literature that could explain the association between mentally stimulating activities and reduced risk of cognitive decline. For example, engaging in leisure activities and thus having an enriched and stimulating environment may induce functional or structural changes in the brain. ${ }^{30}$ This may lead to an enhanced cognitive reserve, which enables persons to better cope with progressing $\mathrm{AD}$ pathology. ${ }^{29,34}$ Furthermore, persons that engage in mentally stimulating activities may have a higher likelihood of exhibiting other healthy lifestyle behaviors that may be protective against cognitive decline, such as physical activity or a healthy diet. Engaging in leisure activities may also be associated with better emotional health, which in turn is associated with cognitive health. Similarly, educational and occupational attainments may be associated with higher mental activities and more preserved cognition. In contrast, comorbid medical conditions may hinder a person in engaging in mentally stimulating activities, which may result in an increased risk of cognitive impairment. To account for these potential covariates, we have adjusted our analyses for education, and additional adjustment for depression (as assessed by Beck Depression Inventory) $)^{35}$ and medical comorbidities (as assessed by Charlson index ${ }^{36}$ had a negligible effect on our findings (data not shown). Finally, it is possible that a reduction in participation in late-life activities may be a proxy for incipient brain disease that is about to become symptomatic.

Our findings should be interpreted in the context of the strengths and limitations of this study. The strengths are the population-based, longitudinal design and the relatively large sample of 2,000 community-dwelling persons aged $\geq 70$ years. Main limitations pertain to the self-reported questionnaire used to assess mentally stimulating activities that may be prone to recall bias. However, using a questionnaire allowed us to assess not only late-life but also midlife engagement in these activities albeit considering that recall bias may particularly be relevant for activities that were carried out in midlife as they may be harder to remember than those carried out within the year prior to the study. Furthermore, as in any observational study, it is not possible to determine a cause- 
Table 4 Association between frequency of engagement in mentally stimulating activities in late life and the risk of incident mild cognitive impairment (MCI)

\begin{tabular}{|c|c|c|c|c|}
\hline Variable & No. at risk & No. with incident $\mathrm{MCl}$ & HR $(95 \% \mathrm{Cl})$ & $p$ Value \\
\hline \multicolumn{5}{|l|}{ Reading books } \\
\hline$\leq$ Once a month & 616 & 191 & 1.00 [reference] & \\
\hline 2-3 times/mo & 265 & 63 & $0.74(0.55-0.99)$ & 0.04 \\
\hline 1-2 times/wk & 173 & 47 & $0.88(0.64-1.22)$ & 0.45 \\
\hline 3-4 times/wk & 210 & 53 & $0.77(0.56-1.05)$ & 0.10 \\
\hline 5-6 times/wk & 211 & 49 & $0.72(0.52-1.00)$ & 0.05 \\
\hline Every day & 525 & 129 & $0.72(0.57-0.91)$ & $<0.01$ \\
\hline \multicolumn{5}{|l|}{ Computer use } \\
\hline$\leq$ Once a month & 808 & 279 & 1.00 [reference] & \\
\hline 2-3 times/mo & 55 & 13 & $0.71(0.41-1.25)$ & 0.23 \\
\hline 1-2 times/wk & 78 & 19 & $0.79(0.50-1.26)$ & 0.32 \\
\hline 3-4 times/wk & 133 & 32 & $0.71(0.49-1.02)$ & 0.07 \\
\hline 5-6 times/wk & 147 & 28 & $0.64(0.43-0.94)$ & 0.02 \\
\hline Every day & 779 & 161 & $0.67(0.55-0.83)$ & $<0.01$ \\
\hline \multicolumn{5}{|l|}{ Craft activities } \\
\hline$\leq$ Once a month & 1,174 & 338 & 1.00 [reference] & \\
\hline 2-3 times/mo & 305 & 67 & $0.67(0.52-0.88)$ & $<0.01$ \\
\hline 1-2 times/wk & 176 & 41 & $0.71(0.51-0.98)$ & 0.04 \\
\hline 3-4 times/wk & 153 & 35 & $0.73(0.51-1.03)$ & 0.07 \\
\hline 5-6 times/wk & 75 & 15 & $0.55(0.33-0.93)$ & 0.02 \\
\hline Every day & 117 & 36 & $0.96(0.67-1.36)$ & 0.80 \\
\hline \multicolumn{5}{|l|}{ Social activities } \\
\hline$\leq$ Once a month & 401 & 136 & 1.00 [reference] & \\
\hline 2-3 times/mo & 802 & 205 & $0.79(0.63-0.98)$ & 0.03 \\
\hline 1-2 times/wk & 524 & 119 & $0.68(0.53-0.87)$ & $<0.01$ \\
\hline 3-4 times/wk & 196 & 50 & $0.69(0.50-0.96)$ & 0.03 \\
\hline 5-6 times/wk & 47 & 13 & $0.90(0.50-1.63)$ & 0.73 \\
\hline Every day & 30 & 9 & $1.15(0.58-2.26)$ & 0.70 \\
\hline \multicolumn{5}{|l|}{ Playing games } \\
\hline$\leq$ Once a month & 525 & 169 & 1.00 [reference] & \\
\hline 2-3 times/mo & 329 & 72 & $0.57(0.43-0.75)$ & $<0.01$ \\
\hline 1-2 times/wk & 278 & 81 & $0.80(0.62-1.05)$ & 0.11 \\
\hline 3-4 times/wk & 199 & 61 & $0.82(0.61-1.10)$ & 0.18 \\
\hline 5-6 times/wk & 178 & 36 & $0.50(0.35-0.72)$ & $<0.01$ \\
\hline Every day & 491 & 113 & $0.61(0.48-0.78)$ & $<0.01$ \\
\hline
\end{tabular}

Abbreviations: $\mathrm{Cl}=$ confidence interval; $\mathrm{HR}=$ hazard ratio.

Models adjusted for age (as the time scale), sex, education, and APOE $\varepsilon 4$ genotype status. 
Table 5 Association between frequency of engagement in mentally stimulating activities in midlife and the risk of incident mild cognitive impairment (MCl)

\begin{tabular}{|c|c|c|c|c|}
\hline Variable & No. at risk & No. with incident $\mathrm{MCl}$ & HR $(95 \% \mathrm{Cl})$ & $p$ Value \\
\hline \multicolumn{5}{|l|}{ Reading books } \\
\hline$\leq$ Once a month & 593 & 177 & 1.00 [reference] & \\
\hline 2-3 times/mo & 336 & 89 & $0.86(0.66-1.11)$ & 0.24 \\
\hline 1-2 times/wk & 226 & 60 & $0.97(0.72-1.30)$ & 0.83 \\
\hline 3-4 times/wk & 243 & 63 & $0.80(0.59-1.08)$ & 0.15 \\
\hline 5-6 times/wk & 172 & 37 & $0.76(0.53-1.10)$ & 0.15 \\
\hline Every day & 430 & 106 & $0.77(0.60-1.00)$ & 0.05 \\
\hline \multicolumn{5}{|l|}{ Computer use } \\
\hline$\leq$ Once a month & 1,095 & 362 & 1.00 [reference] & \\
\hline 2-3 times/mo & 67 & 18 & $1.04(0.64-1.67)$ & 0.89 \\
\hline 1-2 times/wk & 99 & 23 & $0.79(0.52-1.21)$ & 0.28 \\
\hline 3-4 times/wk & 121 & 21 & $0.64(0.41-1.00)$ & 0.05 \\
\hline 5-6 times/wk & 148 & 20 & $0.50(0.32-0.79)$ & $<0.01$ \\
\hline Every day & 470 & 88 & $0.76(0.59-0.97)$ & 0.03 \\
\hline \multicolumn{5}{|l|}{ Craft activities } \\
\hline$\leq$ Once a month & 911 & 247 & 1.00 [reference] & \\
\hline 2-3 times/mo & 345 & 75 & $0.75(0.58-0.98)$ & 0.03 \\
\hline 1-2 times/wk & 286 & 71 & $0.81(0.62-1.05)$ & 0.11 \\
\hline 3-4 times/wk & 219 & 58 & $0.84(0.63-1.13)$ & 0.25 \\
\hline 5-6 times/wk & 112 & 34 & $0.84(0.58-1.21)$ & 0.35 \\
\hline Every day & 127 & 47 & $1.16(0.84-1.60)$ & 0.37 \\
\hline \multicolumn{5}{|l|}{ Social activities } \\
\hline$\leq$ Once a month & 278 & 93 & 1.00 [reference] & \\
\hline 2-3 times/mo & 817 & 213 & $0.74(0.57-0.94)$ & 0.01 \\
\hline 1-2 times/wk & 559 & 131 & $0.66(0.51-0.87)$ & $<0.01$ \\
\hline 3-4 times/wk & 263 & 72 & $0.84(0.62-1.15)$ & 0.29 \\
\hline 5-6 times/wk & 58 & 15 & $0.77(0.44-1.35)$ & 0.36 \\
\hline Every day & 25 & 8 & $1.22(0.59-2.52)$ & 0.60 \\
\hline \multicolumn{5}{|l|}{ Playing games } \\
\hline$\leq$ Once a month & 512 & 162 & 1.00 [reference] & \\
\hline 2-3 times/mo & 447 & 102 & $0.57(0.44-0.73)$ & $<0.01$ \\
\hline 1-2 times/wk & 375 & 99 & $0.68(0.53-0.87)$ & $<0.01$ \\
\hline 3-4 times/wk & 229 & 61 & $0.72(0.53-0.97)$ & 0.03 \\
\hline 5-6 times/wk & 120 & 22 & $0.47(0.30-0.73)$ & $<0.01$ \\
\hline Every day & 317 & 86 & $0.70(0.53-0.91)$ & $<0.01$ \\
\hline
\end{tabular}

Abbreviations: $\mathrm{Cl}=$ confidence interval; $\mathrm{HR}=$ hazard ratio.

Models adjusted for age (as the time scale), sex, education, and APOE \&4 genotype status. 
effect relationship. Therefore, reverse causality may be one potential explanation for our observed associations, i.e., persons with incipient cognitive impairment may be less likely to engage in mentally stimulating activities, particularly in late life, as compared to individuals without incipient cognitive impairment.

We observed evidence of an association between quantity and quality of mentally stimulating activities and a decreased risk of incident MCI. Engaging in a higher number of activities, particularly in late life, appears to be more strongly associated with a decreased risk of incident MCI as compared to engaging in only 1 or 2 activities. Future research, preferably derived from prospective cohort studies, is needed to confirm these findings and to also explore underlying mechanisms that may explain the association between quantity and quality of mentally stimulating activities and the risk of incident MCI.

\section{Study funding}

Support for this research was provided by NIH grants: National Institute on Aging (R01 AG057708; U01 AG006786; P50 AG016574; R01 AG034676) and National Institute of Mental Health (K01 MH068351). This project was also supported by the Robert Wood Johnson Foundation, the Robert H. and Clarice Smith and Abigail Van Buren Alzheimer's Disease Research Program, the GHR Foundation, the Mayo Foundation for Medical Education and Research, the Edli Foundation, and the Arizona Alzheimer's Consortium.

\section{Disclosure}

J. Krell-Roesch receives research funding from the NIH. J.A. Syrjanen reports no disclosures relevant to the manuscript. M. Vassilaki receives research funding from the NIH, Roche, and Biogen. M.M. Machulda receives research funding from the NIH. M.M. Mielke reports consulting for Eli Lilly and Lysosomal Therapeutics, Inc., receiving unrestricted research grants from Biogen and Lundbeck, and research funding from the NIH and the Department of Defense. D.S. Knopman serves on a Data Safety Monitoring Board for the Dominantly Inherited Alzheimer Network Study. He is an investigator in clinical trials sponsored by Lilly Pharmaceuticals, Biogen, and the Alzheimer's Treatment and Research Institute at USC, and receives research support from the NIH. W.K. Kremers receives research funding from the Department of Defense, the NIH, Astra Zeneca, Biogen, and Roche. R.C. Petersen serves as a consultant for Roche, Inc., Merck, Inc., Genentech, Inc., Biogen, Inc., and Eli Lilly, serves on data monitoring committees for Pfizer, Inc., and Janssen Alzheimer Immunotherapy, receives publishing royalties from Mild Cognitive Impairment (Oxford University Press, 2003), and receives research support from the NIH. Y.E. Geda receives funding from the NIH and Roche and served on the Lundbeck Advisory Board. Go to Neurology.org/N for full disclosures.

\section{Publication history}

Received by Neurology November 27, 2018. Accepted in final form March 28, 2019.
Appendix Authors

\begin{tabular}{|c|c|c|c|}
\hline Name & Location & Role & Contribution \\
\hline $\begin{array}{l}\text { Janina Krell- } \\
\text { Roesch, PhD }\end{array}$ & $\begin{array}{l}\text { Mayo Clinic } \\
\text { Scottsdale, } \\
\text { AZ }\end{array}$ & Author & $\begin{array}{l}\text { Study concept and design, } \\
\text { interpretation of results, } \\
\text { drafting of the manuscript }\end{array}$ \\
\hline $\begin{array}{l}\text { Jeremy A. } \\
\text { Syrjanen, } \\
\text { MSc }\end{array}$ & $\begin{array}{l}\text { Mayo Clinic } \\
\text { Rochester, } \\
\text { MN }\end{array}$ & Author & $\begin{array}{l}\text { Data analysis and } \\
\text { interpretation, manuscript } \\
\text { revision }\end{array}$ \\
\hline $\begin{array}{l}\text { Maria } \\
\text { Vassilaki, } \\
\text { MD, PhD, } \\
\text { MPH }\end{array}$ & $\begin{array}{l}\text { Mayo Clinic } \\
\text { Rochester, } \\
\text { MN }\end{array}$ & Author & $\begin{array}{l}\text { Study concept and design, } \\
\text { data acquisition, manuscript } \\
\text { revision }\end{array}$ \\
\hline $\begin{array}{l}\text { Mary M. } \\
\text { Machulda, } \\
\text { PhD }\end{array}$ & $\begin{array}{l}\text { Mayo Clinic } \\
\text { Rochester, } \\
\text { MN }\end{array}$ & Author & $\begin{array}{l}\text { Study concept and design, } \\
\text { data acquisition, manuscript } \\
\text { revision }\end{array}$ \\
\hline $\begin{array}{l}\text { Michelle M. } \\
\text { Mielke, PhD }\end{array}$ & $\begin{array}{l}\text { Mayo Clinic } \\
\text { Rochester, } \\
\text { MN }\end{array}$ & Author & $\begin{array}{l}\text { Study concept and design, } \\
\text { data acquisition, manuscript } \\
\text { revision }\end{array}$ \\
\hline $\begin{array}{l}\text { David S. } \\
\text { Knopman, } \\
\text { MD }\end{array}$ & $\begin{array}{l}\text { Mayo Clinic } \\
\text { Rochester, } \\
\text { MN }\end{array}$ & Author & $\begin{array}{l}\text { Study concept and design, } \\
\text { data acquisition, manuscript } \\
\text { revision }\end{array}$ \\
\hline $\begin{array}{l}\text { Walter K. } \\
\text { Kremers, PhD }\end{array}$ & $\begin{array}{l}\text { Mayo Clinic } \\
\text { Rochester, } \\
\text { MN }\end{array}$ & Author & $\begin{array}{l}\text { Data analysis and } \\
\text { interpretation, manuscript } \\
\text { revision }\end{array}$ \\
\hline $\begin{array}{l}\text { Ronald C. } \\
\text { Petersen, } \\
\text { MD, PhD }\end{array}$ & $\begin{array}{l}\text { Mayo Clinic } \\
\text { Rochester, } \\
\text { MN }\end{array}$ & Author & $\begin{array}{l}\text { Study concept and design, } \\
\text { data acquisition, manuscript } \\
\text { revision, study supervision }\end{array}$ \\
\hline $\begin{array}{l}\text { Yonas E. } \\
\text { Geda, MD, } \\
\text { MSc }\end{array}$ & $\begin{array}{l}\text { Mayo Clinic } \\
\text { Scottsdale, } \\
\text { AZ }\end{array}$ & Author & $\begin{array}{l}\text { Study concept and design, } \\
\text { data acquisition, manuscript } \\
\text { revision, study supervision }\end{array}$ \\
\hline
\end{tabular}

\section{References}

1. Yates LA, Ziser S, Spector A, Orrell M. Cognitive leisure activities and future risk of cognitive impairment and dementia: systematic review and meta-analysis. Int Psychogeriatr 2016;28:1791-1806.

2. Krell-Roesch J, Vemuri P, Pink A, et al. Association between mentally stimulating activities in late life and the outcome of incident mild cognitive impairment, with an analysis of the APOE epsilon4 genotype. JAMA Neurol 2017;74:332-338.

3. Roberts RO, Geda YE, Knopman DS, et al. The Mayo Clinic Study of Aging: design and sampling, participation, baseline measures and sample characteristics. Neuroepidemiology 2008;30:58-69.

4. Kokmen E, Smith GE, Petersen RC, Tangalos E, Ivnik RC. The short test of mental status correlations with standardized psychometric testing. Arch Neurol 1991;48:725-728.

5. Morris JC. The Clinical Dementia Rating (CDR): current version and scoring rules. Neurology 1993;43:2412-2414.

6. Rey A. l'Examen Clinique en Psychologie. Paris: Presses Universitaires de France; 1964.

7. Wechsler D. Wechsler Memory Scale-Revised. New York: The Psychological Corporation; 1987

8. Kaplan E, Goodglass H, Weintraub S. Boston Naming Test, 2nd ed. Philadelphia: Lippincott Williams \& Wilkins, 2001.

9. Lucas JA, Ivnik RJ, Smith GE, et al Mayo's older Americans normative studies: category fluency norms. J Clin Exp Neuropsychol 1998;20:194-200.

10. Wechsler D. Wechsler Adult Intelligence Scale-Revised. New York: Psychological Corporation; 1981.

11. Reitan RM. Validity of the Trail-Making Test as an indicator of organic brain damage. Percept Mot Skills 1958;8:271-276.

12. Ivnik RJ, Malec JF, Smith GE, et al. Mayo's older Americans normative studies: WAISR norms for ages 56 to 97 . Clin Neuropsychol 1992;6:1-30.

13. Ivnik RJ, Malec JF, Smith GE, et al. Mayo's older Americans normative studies: WMS R norms for ages 56 to 94 . Clin Neuropsychol 1992;6:49-82.

14. Ivnik RJ, Malec JF, Smith GE, et al. Mayo's older Americans normative studies: updated AVLT norms for ages 56 to 97. Clin Neuropsychol 1992;6:83-104.

15. Malec JF, Ivnik RJ, Smith GE, et al. Mayo's older Americans normative studies: utility of corrections for age and education for the WAIS-R. Clin Neuropsychol 1992;6: 31-47.

16. Petersen RC. Mild cognitive impairment as a diagnostic entity. J Intern Med 2004; 256:183-194. 
17. Winblad B, Palmer K, Kivipelto M, et al. Mild cognitive impairment: beyond controversies, towards a consensus: report of the International working group on mild cognitive impairment. J Intern Med 2004;256:240-246.

18. Geda YE, Topazian HM, Roberts LA, et al. Engaging in cognitive activities, aging, and mild cognitive impairment: a population-based study. J Neuropsychiatry Clin Neurosci 2011;23:149-154.

19. Roberts RO, Cha RH, Mielke MM, et al. Risk and protective factors for cognitive impairment in persons aged 85 years and older. Neurology 2015;84:1854-1861.

20. Verghese J, Lipton RB, Katz MJ, et al. Leisure activities and the risk of dementia in the elderly. N Engl J Med 2003;348:2508-2516.

21. Wilson RS, Bennett DA, Beckett LA, et al. Cognitive activity in older persons from a geographically defined population. J Gerontol B Psychol Sci Soc Sci 1999;54:P155-P160.

22. Friedland RP, Fritsch T, Smyth KA, et al. Patients with Alzheimer's disease have reduced activities in midlife compared with healthy control-group members. Proc Natl Acad Sci USA 2001;98:3440-3445.

23. Hixson JE, Vernier DT. Restriction isotyping of human apolipoprotein E by gene amplification and cleavage with HhaI. J Lipid Res 1990;31:545-548.

24. Verghese J, LeValley A, Derby C, et al. Leisure activities and the risk of amnestic mild cognitive impairment in the elderly. Neurology 2006;66:821-827.

25. Zhu X, Qiu C, Zeng Y, Li J. Leisure activities, education, and cognitive impairment in Chinese older adults: a population-based longitudinal study. Int Psychogeriatr 2017; 29:727-739.

26. Akbaraly TN, Portet F, Fustinoni S, et al. Leisure activities and the risk of dementia in the elderly: results from the three-city study. Neurology 2009;73:854-861.
27. Marioni RE, Proust-Lima C, Amieva H, et al. Social activity, cognitive decline and dementia risk: a 20-year prospective cohort study. BMC Public Health 2015;15:1089.

28. Wilson RS, Mendes De Leon CF, Barnes LL, et al. Participation in cognitively stimulating activities and risk of incident Alzheimer disease. JAMA 2002;287: 742-748.

29. Wilson RS, Scherr PA, Schneider JA, Tang Y, Bennett DA. Relation of cognitive activity to risk of developing Alzheimer disease. Neurology 2007;69:1911-1920.

30. Scarmeas N, Levy G, Tang MX, Manly J, Stern Y. Influence of leisure activity on the incidence of Alzheimer's disease. Neurology 2001;57:2236-2242.

31. Wang HX, Jin Y, Hendrie HC, et al. Late life leisure activities and risk of cognitive decline. J Gerontol A Biol Sci Med Sci 2013;68:205-213.

32. Andel R, Silverstein M, Kåreholt I. The role of midlife occupational complexity and leisure activity in late-life cognition. J Gerontol B Psychol Sci Soc Sci 2015;70: 314-321.

33. Gow AJ, Pattie A, Deary IJ. Lifecourse activity participation from Early, mid, and later adulthood as determinants of cognitive aging: the Lothian Birth cohort 1921 J Gerontol B Psychol Sci Soc Sci 2017;72:25-37.

34. Scarmeas N, Stern Y. Cognitive reserve and lifestyle. J Clin Exp Neuropsychol 2003; 25:625-633.

35. Beck AT, Steer RA, Brown GK. BDI-II, Beck Depression Inventory: Manual, 2nd ed. San Antonio: Psychological Corp.; Harcourt Brace; 1996.

36. Charlson ME, Pompei P, Ales KL, MacKenzie CR. A new method of classifying prognostic comorbidity in longitudinal studies: development and validation. J Chronic Dis 1987;40:373-383. 


\section{Neurology}

\section{Quantity and quality of mental activities and the risk of incident mild cognitive impairment}

Janina Krell-Roesch, Jeremy A. Syrjanen, Maria Vassilaki, et al.

Neurology 2019;93;e548-e558 Published Online before print July 10, 2019

DOI 10.1212/WNL.0000000000007897

This information is current as of July 10, 2019

\section{Updated Information \& Services}

References

Citations

Subspecialty Collections

Permissions \& Licensing

Reprints including high resolution figures, can be found at: http://n.neurology.org/content/93/6/e548.full

This article cites 31 articles, 8 of which you can access for free at: http://n.neurology.org/content/93/6/e548.full\#ref-list-1

This article has been cited by 1 HighWire-hosted articles: http://n.neurology.org/content/93/6/e548.full\#\#otherarticles

This article, along with others on similar topics, appears in the following collection(s):

\section{Cognitive aging}

http://n.neurology.org/cgi/collection/cognitive_aging

Cohort studies

http://n.neurology.org/cgi/collection/cohort_studies

MCI (mild cognitive impairment)

http://n.neurology.org/cgi/collection/mci_mild_cognitive_impairment

Information about reproducing this article in parts (figures,tables) or in its entirety can be found online at:

http://www.neurology.org/about/about_the_journal\#permissions

Information about ordering reprints can be found online:

http://n.neurology.org/subscribers/advertise

Neurology ${ }^{\circledR}$ is the official journal of the American Academy of Neurology. Published continuously since 1951, it is now a weekly with 48 issues per year. Copyright Copyright ( 2019 The Author(s). Published by Wolters Kluwer Health, Inc. on behalf of the American Academy of Neurology.. All rights reserved. Print ISSN: 0028-3878. Online ISSN: 1526-632X.

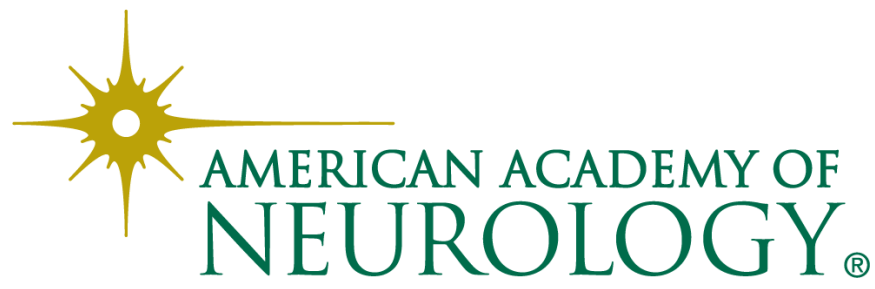

